\title{
Who Owns Renewable Energy Certificates?
}

Edward Holt, Ryan Wiser and Mark Bolinger

For review and comments, please contact the lead author:

Edward A. Holt

Ed Holt \& Associates, Inc.

28 Headland Road

Harpswell, ME 04079

(207) 798-4588

edholt@igc.org

Renewable energy certificates (RECs) are tradable instruments that convey the attributes of a renewable energy generator and the right to make certain claims about energy purchases. RECs first appeared in US markets in the late 1990s and are particularly important in states that accept or require them as evidence of compliance with renewables portfolio standards (RPS). The emergence of RECs as a tradable commodity has made utilities, generators, and regulators increasingly aware of the need to specify who owns the RECs in energy transactions.

In voluntary transactions, most agree that the question of REC ownership can and should be negotiated privately between the buyer and the seller, and should be clearly established by contract. Claims about purchasing or using renewable energy should only be made if REC ownership can be documented.

In many other cases, however, renewable energy transactions are either mandated or encouraged through state or federal policy. Because of the recent appearance of RECs, legislation and regulation mandating the purchase of renewable energy has sometimes been silent on the disposition of the RECs associated with that generation. Furthermore, some renewable energy contracts pre-date the existence of RECs, and therefore do not address REC ownership. In both of these instances, the issue of REC ownership must often be answered by legislative or regulatory authorities. The resulting uncertainty in REC ownership has hindered the development of robust REC markets and has, in some cases, led to contention between buyers and sellers of renewable generation.

This article, which is based on a longer Berkeley Lab report, ${ }^{1}$ reviews federal and state efforts to clarify the ownership of RECs from Qualifying Facilities (QFs) that sell their generation under the Public Utility Regulatory Policies Act (PURPA) of 1978. The full report also addresses state efforts to clarify REC ownership in two other situations, customer-owned generation that benefits from state net metering rules, and generation facilities that receive financial incentives from state or utility funds.

The issue of REC ownership most often arises in states that have adopted an RPS. In such states, both parties to QF contracts have a lot at stake: either additional cost to a utility if RECs are awarded to the QF, or loss of value to the QF if RECs are awarded to the

\footnotetext{
${ }^{1}$ The full report, "Who Owns Renewable Energy Certificates: An Exploration of Policy Options and Practice," may be found at http://eetd.lbl.gov/ea/EMS/re-pubs.html.
} 
utility. As a rough estimate, QF RECs that are eligible for state RPS programs could have a value between $\$ 35$ million and $\$ 175$ million, ${ }^{2}$ so there is significant economic value riding on the ownership question.

\section{FERC Decides....Or Does It?}

In 2003, uncertainty about who owns the RECs in mandated QF contracts with utilities led to a petition to FERC to issue a declaratory judgment on the question as it relates to Section 210 of PURPA. FERC declared that avoided cost payments mandated by PURPA pay only for energy and capacity and do not convey the renewable attributes, absent explicit contractual language to the contrary. FERC stated that PURPA does not address the ownership of RECs and that " the Commission's avoided cost regulations did not contemplate the existence of RECs." But FERC also declared that RECs are the creation of states and that states may decide the question, but that the decision must be based on state law, not on PURPA. ${ }^{3}$

In denying a rehearing, FERC emphasized that avoided cost rates do not compensate for more than energy and capacity. It reached this conclusion in part because energy from fossil-fuel fired cogeneration is priced the same as energy from a renewable small power production facility. If avoided cost rates do not compensate a QF from more than energy and capacity, FERC reasoned, "it follows that other attributes associated with the facilities are separate from, and may be sold separately from, the capacity and energy."

In a footnote to this statement, FERC noted that

"...cogeneration facilities, to receive QF status, are required to produce both electricity and useful thermal output... The thermal output that is a pre-requisite to a cogeneration facility's achieving QF status is saleable separately from the capacity and energy of the cogeneration facility...If the thermal output of a cogeneration QF is separately saleable, the renewable attributes of a small power production $\mathrm{QF}$ are similarly separate."

Qualifying Facilities were initially pleased with the FERC Order because they interpreted it to mean that utilities must pay separately, in addition to avoided costs, for the RECs. The FERC Order, however, left QF contracts in an unsettled state by simultaneously finding that states are the appropriate venue in which to determine REC ownership, as long as states do not base their decisions on PURPA avoided cost payments. As a result, the focus has shifted to the states, with the contenders on both sides of the issue often citing the FERC Order to bolster their cases.

\footnotetext{
${ }^{2}$ According to the US EIA, in 1996, renewable QFs produced 68,594,000 MWh, and that number has been rising. The value estimate assumes that only half of them are eligible for RPS programs, and that they are worth from $\$ 1$ to $\$ 5$ per REC, a conservative assumption.

${ }^{3}$ See FERC Docket No. EL03-133-000, Petition for Declaratory Order and Request for Expedited Consideration, American Ref-Fuel Company, Covanta Energy Group, Montenay Power Corporation, and Wheelabrator Technologies, Inc. June 16, 2003; Order Granting Petition for Declaratory Ruling, October 1, 2003. American Ref-Fuel Co. et al., 105 FERC \ 61,004 (2003); and Order Denying Rehearing. April 15, 2004. 107 FERC \ 61,016 (2004).
} 


\section{The Argument Moves to the States}

Sixteen states have addressed REC ownership in QF or other existing contracts, either explicitly or implicitly. In all but one case (New Mexico) the determination of QF REC ownership has been made by state regulation, as opposed to legislation, though in many instances these determinations have been informed by legislative guidance. We examined the record in seven states where the issue has been debated extensively among parties and where the record is readily available.

A wide variety of arguments have been presented on both sides of the issue. We summarize some of the major arguments and counter-arguments below in order to convey the nature of the debate that is occurring and the issues on which state regulators are deciding.

One of the threshold issues in the debate (despite the FERC ruling) is whether PURPA itself requires that RECs be transferred to the utility purchasers, through its qualification requirements. Utilities, for example, have argued that the renewable attributes are inextricably tied to QF sales of energy. The fact that a facility is renewable is what obligates a utility to purchase its power under PURPA. A utility would not be obligated to enter into a contract absent the facility's status as a "small renewable power project." Therefore ownership of the RECs must remain with the utility if its customers are to receive full value for the cost of this resource.

QFs counter that the PURPA requirement to purchase electricity from renewable QFs does not mean that contracts must convey the RECs to the utilities. Being renewable is merely a qualifying characteristic that makes a generating facility eligible for a contract, and does not require transfer of the attributes. The FERC Order supports this distinction and affirms that RECs are not automatically transferred to the purchasing utility.

Related debate also centers on compensation for RECs. Utilities generally argue that under state law, payments are intended to compensate the QF for the entire output of the facility, including its non-power characteristics. In fact, in some states, QFs submit affidavits to the purchasing utilities attesting that the power sold is renewable energy. This, the utilities argue, proves that they are being sold the renewable attributes.

QFs respond that the FERC Order states that avoided costs are not intended to compensate the QF for more than energy and capacity. Further, they say that it is clear that avoided cost payments do not compensate for RECs because renewable QFs are paid the same avoided costs as are fossil-fueled cogeneration QFs. Therefore avoided cost payments by utilities compensate only for energy and capacity, and not for environmental benefits. QFs in some states have also argued that state calculations of avoided cost are currently based on costs associated with fossil fuel-fired plants that do not have associated RECs. They conclude, therefore, that avoided cost compensation does not include any recognition of the economic value of the RECs. 
In Colorado, QFs argued that when a contract does not expressly convey RECs, those severable property interests are reserved for the seller. They say that a utility can only be entitled to those products specifically enumerated in a contract.

The utility argued the opposite, that when an asset or commodity is not specifically reserved for the seller, the full asset or commodity is deemed to have been transferred to the buyer.

Some of the compensation arguments focus on the question of fairness. Utilities say that renewable QFs are already fairly compensated based on a stream of guaranteed payments, which QF owners presumably judge to be sufficient to earn a return on their investment.

QFs respond that payments are not related to QF economic needs, but depend solely on the utility's avoided cost for energy and capacity.

Utilities also argue that they and their ratepayers are already paying above-market prices for QF contracts and therefore customers should receive all the benefits of this energy.

QFs answer that although many QF contracts have turned out to be expensive relative to market prices, the absolute price payable under a QF agreement is not relevant to determining the parties' intent with regard to REC transfer. They say that a contract cannot be interpreted in light of subsequent changes in market prices. They conclude that QFs must be paid the avoided cost in effect when the agreement was made.

Utilities argue that requiring them to pay extra for RECs would be a windfall gain to QFs that were satisfied with contract terms entered into long ago without the promise of supplementary remuneration in the future.

In reply, QFs maintain that requiring QFs to transfer RECs with energy without additional compensation would provide a windfall to utilities that were satisfied with contract terms entered into long ago without the promise of supplementary values in the future.

QFs also argue that awarding RECs to utilities in exchange for their originally contracted purchase price is tantamount to a reduction in price after the agreements were made. They maintain that purchase prices agreed to at the time of the PURPA contract cannot be revisited by state commissions.

Utilities counter that there is no change in price because nothing different is being conveyed than before RECs were invented.

On another issue, QFs maintain that regulatory assignment of RECs to the utilities without just compensation would constitute an unconstitutional taking of private property in violation of the Fifth and Fourteenth Amendments to the US Constitution, and would obligate the state to compensate the QFs for the value of RECs. 
Utilities and others argue that there is no entitlement to compensation for RECs because (1) there is no reasonable expectation of protection, for example, a statute conferring property rights in RECs; (2) the restriction on RECs does not deprive the QF of all economic value attached to its property; and (3) restrictions on property may be allowed as long as they promote the general welfare. They say that the fact that a property interest cannot be fully exploited is not sufficient to turn government restrictions into a compensable taking.

The effect of unbundling RECs from the sale of energy also sparks opposing viewpoints. QFs argue that RECs are not mentioned in the contracts as being transferred. Electric energy sales do not transfer products that are unbundled from the energy and capacity sold.

Utilities maintain that even though RECs were not contemplated at the time the QF contracts were signed, the QF transactions were, in effect, a bundled sale of energy and attributes that at the time represented a single product.

QFs state that RECs are a new product that must be contracted for and sold pursuant to its own terms separately from the energy and capacity.

Utilities disagree, reasoning that RECs were being conveyed with PURPA contracts even before they were recognized and valued. Just because an attribute subsequently acquires a separate market value does not mean that it now warrants separate compensation

QFs also contend that state RPS programs and regional REC tracking systems provide for the creation of unbundled certificates. If RECs are unbundled commodities, they maintain, it cannot be argued that they are automatically transferred with the sale of power as an inseparable part of the QF output.

Utilities dispute this interpretation, arguing that the adoption of a system that allows for unbundling does not transform the essential nature of a QF contract as a bundled transaction into one that includes only the commodity.

Some of the arguments relate to the balancing of risks and rewards. As utilities see it, by accepting a QF contract, the generator avoids the risk of market forces and is entitled to a long-term, assured revenue stream, while the utility is guaranteed cost-recovery by the regulatory commission. They contend that the energy market risk is shifted to the utility and its ratepayers. By now asserting ownership of the RECs, the utilities think, the QF seeks to retain the benefits of PURPA protection but gain the benefits of market participation through the separate sale of RECs.

Naturally, QFs see things differently. In their view, if utilities are granted ownership of all renewable attributes (RECs), they should also be responsible for the environmental attributes and liabilities of non-renewable power plants from which they purchase but do not own - contingencies that are not recognized on the utilities' books. QFs reason that a 
utility should not be able to pick and choose which attributes it would like to own among all the purchased energy for which it contracts.

The presence of an RPS, which drives many of these debates, also leads to some different arguments. For example, utilities believe that for RPS compliance they should be deemed to have purchased the attributes of the power from the QFs and should be able to count the RECs towards meeting the RPS. They state that granting the RECs to the utility would reduce RPS compliance costs borne by ratepayers.

QFs rejoin that payment for RECs may be critical to a project's economic feasibility. In their view, the sale of RECs separate from power is intended to compensate the owner of the renewable facility and promote further investment in renewable resources. Because the risks of development and operation of a renewable facility are borne by the QF owner, the rewards associated with RECs should also accrue to the QF.

Utilities also argue that in states with an RPS, awarding the RECs to the QFs would result in the utilities having to pay the QFs twice - once for energy and capacity based on avoided cost, and a second time for RECs - for no additional benefit to ratepayers.

QFs respond that utilities and ratepayers receive the benefits of renewable energy even without the RECs: increased fuel diversity, a local and secure fuel supply, increased efficiency of energy production, and a fixed price not subject to the vagaries of world commodity markets.

Utilities claim that RPS laws are intended to encourage the construction of new renewable resources, and not to pay more for RECs from existing renewable resources that already sell their output to the utility.

The QF perspective is that RPS laws intend that the requirement be met in the most costeffective manner, which includes purchasing RECs associated with any given contract, whether from a new generator or an existing QF.

Not every argument is made in every state, of course, because each state has a different legal context. However, it is noticeable that some arguments are picked up and refined in states that subsequently open a proceeding on REC ownership. Clearly, both sides are trying to learn from prior proceedings and pick the most convincing and persuasive points.

\section{$\underline{\text { States Decide }}$}

It is readily apparent that there is no conciliating most of these arguments. State regulatory commissions have had to weigh these arguments in light of state law, rules and precedent.

Table 1 summarizes state determinations so far on the ownership of RECs within the context of QF generation and PURPA. Treatment of REC ownership varies significantly 
based on whether the QF contract pre-dates a specific regulatory determination or whether the regulation applies to new QF contracts (or at least post-dates a regulatory determination). The older pre-existing contracts are generally silent on the issue of ownership and therefore present a greater challenge, but without guidance, buyers and sellers may be stalemated in negotiation of new contracts as well.

In most cases, states have opted to establish that the utility purchaser will have title to the underlying RECs for existing QF contracts, while several states award RECs resulting from new contracts to the QF. Such determinations are especially common in states with RPS mandates where existing renewable generation is eligible. In these instances, state policymakers are apparently concerned that conveyance of RECs to existing QF generators would unnecessarily raise the cost of the RPS policy. Though a large number of states have ruled on the issue of QF REC ownership, some of these rulings have been appealed in state and federal courts, and some uncertainty therefore remains. ${ }^{4}$

\section{Table 1. State Positions on REC Ownership under PURPA QF Contracts}

\begin{tabular}{|c|c|c|}
\hline $\begin{array}{l}\text { RECs Conveyed to Power } \\
\text { Purchaser }\end{array}$ & $\begin{array}{l}\text { Proceeding in Process } \\
\quad(\leftarrow \text { leaning } \rightarrow)\end{array}$ & $\begin{array}{l}\text { RECs Retained by QF Unless } \\
\text { Otherwise Stated in Contract }\end{array}$ \\
\hline CT (existing) & $\mathrm{AZ} \rightarrow$ & $\mathrm{CO}($ new $)$ \\
\hline CO (existing) & $\leftarrow \mathrm{CA}$ (existing)* & $\mathrm{NV}$ (new) \\
\hline ME (existing)* & PA & OR (new) \\
\hline MN (existing)** & & RI (new) \\
\hline ND (existing and new, with & & $\mathrm{TX}$ (new) \\
\hline compensation) & & UT (new) \\
\hline NJ (existing) & & \\
\hline NM (existing and new) & & \\
\hline NV (existing) & & \\
\hline TX (existing) & & \\
\hline WI (existing)** & & \\
\hline
\end{tabular}

* Maine and California currently count PURPA QF contracts towards RPS, without specifically requiring RECs to be transferred to the buyer.

** Renewable attributes appear to be conveyed with underlying energy deliveries, by default, for purpose of compliance with state RPS requirements, but treatment of RECs is not stated clearly.

\section{Conclusions}

Given FERC's 2003 ruling, and the fact that more and more states have adopted policies in which RECs are recognized, if not required, for RPS compliance, pressure has been mounting on the states to address the question of REC ownership. This is critical for QF contracts because RECs from these facilities are material to compliance with state

\footnotetext{
${ }^{4}$ Appeals of state regulatory decisions to state or federal courts are pending in Connecticut, New Jersey and Colorado.
} 
renewable portfolio standards, or may otherwise be sold in voluntary markets. The quantity of RECs from QFs, and potentially their value, is significant.

On a longer-term basis, issues of REC ownership may diminish. New QF contracts are more likely than older contracts to clearly specify REC disposition. The number of QF contracts is also likely to diminish with the passage of the Energy Policy Act of 2005. EPAct 2005 does not affect existing QF contracts, but prospectively, FERC may end the utility purchase obligation on a regional basis if it finds that a wholesale electricity market is competitive, affording generators non-discriminatory access to sell their power. In time this will result in less tension and conflict.

In the meantime, state policymakers will play a critical role in ownership determinations, and some degree of confusion and uncertainty will likely remain. Most of the determinations have thus far occurred through state regulatory action. Absent further clarification from FERC on the issue of QF REC ownership, however, in the future states may wish to determine REC ownership through state legislation. Though regulatory action has been the more common approach to date, those decisions have sometimes been appealed to the courts. State legislative action may reduce such appeals.

Edward Holt is president of Ed Holt \& Associates, Inc. in Harpswell, ME and may be contacted at edholt@igc.org. Ryan Wiser (hwiser@lbl.gov) and Mark Bolinger (mabolinger@lbl.gov) are with Lawrence Berkeley National Laboratory in Berkeley, CA. The work described in this article was funded by the Office of Electricity Delivery and Energy Reliability, Permitting, Siting and Analysis of the U.S. Department of Energy under Contract No. DE-AC02-05CH11231. 